\title{
A CONCEPÇÃO DE FREGE SOBRE “SENTIDO” E "REFERÊNCIA" COMO INFLUÊNCIA NO ESTUDO DA FILOSOFIA DA LINGUAGEM
}

\author{
Máximo Gustavo Rodríguez de Melo ${ }^{1}$
}

Resumo: Este artigo tem como objetivo expor e discutir as concepções de Gottlob Frege sobre os conceitos de "sentido" e "referência" e como, por meio destes, se deu a contribuição do filósofo ao que hoje chamamos filosofia da linguagem. Entretanto, vários estudiosos não consideram Frege um autêntico filósofo da linguagem, alguns de seus escritos representam, historicamente, enorme influência nesse ramo da filosofia contemporânea, pois tentam solucionar certos problemas da linguagem. Serão analisados principalmente o célebre artigo "Sobre Sentido e Referência" bem como alguns de seus escritos que se ocupam, ainda que de modo secundário, sobre ambos os conceitos.

Palavras-chave: Sentido; Referencia; Filosofia da Linguagem.

\footnotetext{
${ }^{1}$ Graduando em Filosofia pela Universidade Federal do Pará - UFPA. E-mail: maxrodmelo@ outlook.com.
} 


\section{Introdução}

Apesar dos filósofos sempre discorrerem sobre assuntos referentes à linguagem, procuraremos neste artigo expor e fundamentar a influência de Gottlob Frege (1848-1925), para o surgimento da Filosofia da Linguagem propriamente dita.

Partindo da discussão acerca da identidade formal, Frege faz a distinção dos dois principais conceitos aqui tratados, que na tradução feita por Sergio Miranda são ditos respectivamente como Sentido e Referência ${ }^{2}$.

Tal distinção é realizada na primeira metade do escrito que por sua vez é ocupado na segunda metade com possíveis respostas à críticas.

Iniciaremos, portanto, expondo algumas características do projeto de Frege que o levou a formular seus escritos sobre identidade, contextualizando seus argumentos e, em seguida, trataremos especificamente das bases em que se sustentam o pensamento do autor, buscando identificar quais são os principais argumentos levantados para defender sua posição.

Dando continuidade, examinaremos o distanciamento da filosofia tradicional tomado por Frege - aspecto este que adquire extrema originalidade na obra do autor - e, subsequentemente, ressaltaremos o papel do conceito de identidade. Finalmente, trataremos da influência pelo matemático alemão proporcionada especificamente pela distinção sentido e referência para o surgimento da Filosofia da Linguagem.

$\mathrm{Na}$ conclusão sintetizaremos o que foi exposto a fins didáticos, tentando ressaltar os principais pontos e indicar o peso da contribuição fregiana.

Trataremos neste artigo, dentre os vários escritos que ganharam notoriedade, da "Conceitografia" e principalmente "Sobre Sentido e Referência" haja vista se tratar de um artigo ambicioso, que inicia com certa indagação acerca da identidade não resolvida na própria "Conceitografia" e nos fornece a base de nosso estudo. Para nossos objetivos ainda cabe ressaltar o apoio de literatura secundária indicada na bibliografia.

\section{Os escritos de Frege visam fundamentar seu projeto matemático.}

Frege, inspirado pela filosofia kantiana, tenta, durante parte significativa de sua vida acadêmica provar sua tese logicista de que a aritmética pode ser compreendida analiticamente e não sinteticamente e, para isso, formula alguns escritos de caráter propedêutico referente a tal objetivo que por sua vez são considerados filosóficos e tratam da linguagem formal, visando propor uma linguagem pautada estritamente na lógica, pois, como o matemático

\footnotetext{
${ }^{2}$ Sinn e Bedeutung, respectivamente, do alemão original publicado em 1892.
} 
alemão aponta, as línguas naturais possuem certa falha e, para dar continuidade a seu ambicioso projeto, precisa criar uma linguagem segura pautada na comprovação lógica diferente da utilizada pragmaticamente.

O matemático alemão admite que a linguagem, apesar de eventualmente proporcionar imprecisões que possam levar a erros, ainda assim, é necessária e não tem de ser aniquilada, mas necessita ser fundada em um rigor logico-comprovativo. Sobre esta concepção de Frege, diz Sofia Miguens (2007, p. 84):

Para Frege, a linguagem, e muito especialmente a linguagem natural, é apenas um 'meio' de expressão do pensamento, e um meio que frequentemente obscurece este. Frege admite no entanto que não há outra forma de aceder ao pensamento que não seja a linguagem.

Toda argumentação do filosofo alemão será direcionada e esta teoria logicista que por razões maiores foi abandonada, entretanto, os escritos para fundamentá-la são de extrema importância para se entender a Filosofia da Linguagem como é feita desde seu surgimento.

\section{Aspectos do pensamento de Frege fundamentais para a distinção entre sentido e referência.}

O artigo "Sobre Sentido e Referência" tem como ponto de partida o problema do signo de identidade de conteúdo formal, que é trazido à tona com o intuito de corrigir certo equívoco cometido em "Conceitografia".

Esta problemática, bem como a solução prestada a esta, dará base para toda argumentação posterior do filosofo alemão. Concisamente, poderíamos expor o problema: como se dá a relação de igualdade entre coisas? $O$ que proporcionará identidade, compreendida como a relação que uma coisa mantém consigo mesma e não com as outras, será o modo como nós nos referimos, por "nomes próprios" ou o objeto real existente no mundo, a própria coisa? Ou: "A igualdade desafia a reflexão com questões a seu respeito que não são fáceis de responder. Ela é uma relação? Uma relação entre objetos? Ou entre nomes ou símbolos de objetos?” (FREGE, 1999, p. 21).

Ainda no inicio de "Sobre Sentido e Referencia" é descartada a relevância dos símbolos de objetos, i.e., nomes próprios, como essenciais para fundamentar uma identidade formal, pois para o autor, o nome utilizado para se referir a uma coisa é arbitrário, sendo unicamente determinado por convenções.

Não se admite, portanto, que os nomes tenham um significado absoluto válido para todas as sentenças, mas sim, diferentes significados em diferentes expressões. 
A concepção sobre a identidade se relacionar com os símbolos foi admitida em "Conceitografia". Todavia, nada impede que simbolizemos com "VI" ou "6" o número seis, somente as convenções impostas numa situação especifica. Precisamente:

É certo que em um conjunto perfeito de símbolos cada expressão deveria corresponder a um sentido; mas a linguagem comum não satisfaz muitas vezes essa exigência, e devemos já ficar satisfeitos se no mesmo contexto a mesma palavra tiver sempre o mesmo sentido. (FREGE, 1999, p. 23)

Não obstante, sabendo que o significado é exposto por algum nome próprio, resta considerar, como é possível a compreensão de uma sentença haja vista tal subjetividade. Para o filosofo alemão, o entendimento das expressões está ligado com o conhecimento de cada falante da língua, i.e., na medida em que há o entendimento básico de alguém direcionado a determinada linguagem, este deve ser capaz de compreender o que é dito por ela.

Tendo-se admitido a subjetividade dos nomes próprios é exposta a concepção dita como fundamental para o surgimento da Filosofia da Linguagem, a distinção entre Sentido e Referência.

\section{Sentido e Referência e Identidade.}

Se os nomes próprios não são suficientes no que se refere a identidade, definida pelo filósofo de modo relacional, como: "uma relação que cada coisa mantém consigo mesma, mas que nenhuma mantém com outra" (FREGE, 1999, p. 21), precisamos considerar, então, outros âmbitos para além dos símbolos para compreender a identidade tal como é concebida na obra do filósofo.

Suscintamente, podemos definir Sentido como uma anunciação ligada ao pensamento objetivo, em que "está contido o modo de apresentação" (FREGE, 2011, p.22) e a Referência correspondente ao objeto real do que o sentido apresenta, assim "cumpre o papel de valor semântico das expressões da linguagem formal de Frege” (RODRIGUES, 2008, p. 12).

Vale ressaltar que em Frege torna-se inviável o uso de uma referência apoiada unicamente por aparatos sensoriais subjetivos, devido as consequências da "representação" que as experiências causam a quem as sofre. Para o filosofo alemão, a representação, através da sensibilidade, forma uma imagem interna para o sujeito, e assim sendo, bastante subjetivo, flexível e individual. Portanto, quando se estar a falar de coisas no mundo, expondo seu sentido, cada ouvinte ou interlocutor é passível de, por sua interpretação, representar de seu próprio modo a própria coisa. Lauro Baldini (2011, p. 11) aponta a relação desses conceitos: 


\section{REVISTA APOENA - Per. dos Dis. de Fil. da UFPA \\ Belém, 2019, V. 1, N.1.}

Só podemos falar de algo no mundo, de um objeto, dando-lhe uma descrição. Isso é o sentido. Mas o objeto permanece lá, e essa é a referência. E, no interior de cada consciência, os indivíduos farão representações distintas desse objeto.

A subjetividade advinda da representação é ocasionada quando se toma a relação tradicional filosófica de Sujeito-Objeto e Frege se distancia desta perspectiva, em lugar disto, o uso objetivo do pensamento lógico.

É considerada a identidade como uma relação entre objetos, se assim o fosse, expressões que não fossem tautológicas, que necessitem de conhecimento especifico para serem dadas como validas, como "A Estrela da Manhã é a Estrela da Tarde", estariam prejudicadas pois: “[...] se a identidade for apenas uma relação entre objetos, todas as sentenças de identidade seriam equivalentes a sentenças do tipo $\mathrm{a}=\mathrm{a}$, o que não pode ser $\mathrm{o}$ caso [...].” (RODRIGUES, 2008, p. 11).

Portanto, somente os nomes próprios e somente a referência não irão satisfazer a identidade formal fregiana. Assim, o teórico alemão considera que a identidade será pautada numa referência, relacionado ao sentido, e pautada na comprovação lógica. Ao passo que, o nome será apenas o modo de apresentação da coisa, como uma etiqueta e a identidade, por sua vez, há de ser compreendida e logicamente comprovada.

A conexão regular entre o símbolo, seu sentido e a sua referência é tal que ao símbolo corresponde um sentido determinado, que por sua vez corresponde a uma referência determinada, enquanto à referência (a um objeto) não é só um símbolo que lhe corresponde. $\mathrm{O}$ mesmo sentido tem diferentes expressões em linguagens diferentes, até na mesma linguagem. (FREGE, 1999, p. 23).

Em suma, a identidade para Frege admitida em "Sobre Sentido e Referência" já não dependerá dos nomes próprios, que são, por sua vez, somente uma apresentação do objeto e o modo conceptual com o qual designamos as coisas, darão a identidade e no que segue a este raciocínio, a identidade é compreendida como uma relação entre referência mediante o sentido (comprovada logicamente) ou como diz Abílio Rodrigues (2008):

A conclusão de Frege é que, além do símbolo e daquilo que é nomeado pelo símbolo, que agora é denominado referência, precisamos de mais um elemento, que é o sentido. Frege caracteriza o sentido, no caso de nomes próprios, como o modo de apresentação do objeto designado. A identidade não é mais, como na $C G$, uma relação entre nomes, mas também não é uma relação apenas entre objetos. A identidade é uma relação entre objetos, mas mediada pelo sentido. (RODRIGUES, A. 2008, p. 15).

Cumpre-se necessário ainda a relação entre nomes, sentido e referencia, deixando claro que se expõe o sentido das referências mundanas pelos nomes próprios, sendo assim: 
Um nome próprio (palavra, símbolo, combinação de símbolos, expressão) exprime o seu sentido, refere-se a ou designa a sua referência. Exprimimos com um símbolo o seu sentido e designamos com ele a sua referência. (FREGE, 1999. p. 26)

\section{Referência como fundando o valor de verdade distante da representação.}

Entretanto, se em uma sentença mudamos o seu nome/símbolo, e não alterarmos a referência, seu valor de verdade permanecerá. p. ex. em "O Satélite natural da terra" e "A Lua”, são modos diferentes de nos referirmos a um mesmo objeto real, que, no entanto, permanece o mesmo, mantendo assim o valor de verdade intocável. Frege expõe essas noções:

Talvez se possa conceder que uma expressão, que seja gramaticalmente bem construída e que tenha a função nome próprio, tenha sempre o mesmo sentido. Entretanto, por esse meio não fica estabelecido que ao sentido corresponda também uma referência. A expressão "o corpo celeste mais afastado da Terra" tem um sentido; mas é bastante duvidoso se ela tem também uma referência. A expressão "a série menos convergente" tem um sentido; mas prova-se que ela não tem referência, à medida que se pode encontrar para cada série convergente uma outra que seja ainda convergente. Portanto, mesmo que se apreenda o sentido, não se tem ainda com segurança uma referência. (FREGE, 1999 p. 23.)

É oportuno ressaltar ainda que ambos conceitos - Sentido e Referência - são independentes. Para o autor a referência não é conhecida por nós integralmente, somente em partes, por esse motivo, uma referência pode ter diferentes sentidos, bem como um enunciado possuir determinado sentido e não denotar nada no mundo. Assim, é excluída a possibilidade de que possamos conhecer piamente os objetos, mas somente mediado pela linguagem. Ipses litterum:

O sentido de um nome próprio será apreendido por qualquer um que conheça suficientemente a linguagem ou o conjunto das designações à qual ele pertença; nesse caso, contudo, a referência, caso ela exista, sempre será focada apenas parcialmente. $\mathrm{O}$ conhecimento completo da referência exigiria que pudéssemos dizer imediatamente se um dado sentido a ela pertence. Jamais chegamos a esse ponto. (FREGE, 1999. p. 22-23)

\section{O direcionamento tomado a partir das considerações de Frege influenciou o surgimento da Filosofia da Linguagem}

É conhecido, pelos livros de história da filosofia, que a linguagem é discutida desde os antigos gregos ${ }^{3}$. Todavia, se a linguagem é discutida desde os primórdios da filosofia, qual o papel de Frege, um matemático alemão do final do século XIX e início do XX, quanto ao surgimento da Filosofia da Linguagem?

\footnotetext{
${ }^{3}$ Citemos A Republica e Crátilo de Platão e Da Interpretação de Aristóteles, por exemplo como obras que já tratavam, de algum modo, a origem e funcionamento da linguagem.
} 
O primeiro a se considerar é: a filosofia da linguagem tem como "objeto de estudo" o funcionamento da linguagem distante, em certa perspectiva, do âmbito epistemológico. Ainda que os gregos antigos tenham, em sua época, se dedicado a estudar certos aspectos da linguagem, tais como análise sobre as falas, nomes próprios, verbos, etc., é a partir da distinção fregiana de sentido e referência que a filosofia da linguagem passa a esboçar-se.

Frege, em todo caso, é tido mais próximo ao que se pode chamar a "epistemólogo", pois suas analises são justapostas à epistemologia, i.e., na aplicação em determinado âmbito cientifico, não em uma análise lógica posterior à análise cientifica. Por motivos de os problemas fregianos não serem os mesmos que os tratados pelos filósofos da linguagem, não o consideram como um pensador deste nicho:

Frege não estava interessado no funcionamento da linguagem natural e no modo pelo qual as expressões linguísticas se conectam com o mundo. Em outras palavras, Frege não tinha o menor interesse em construir uma teoria semântica aplicável à linguagem natural. Por essa razão, Frege não foi um filósofo da linguagem. (RODRIGUES, 2008, p. 2).

Apesar de o filosofo alemão haver proporcionado o que se tem como as bases que impulsionaram o início deste ramo da filosofia, a saber, a filosofia da linguagem, ele não era um genuíno filosofo deste tipo, pois, seus escritos tem por objetivo, como dito, propor uma linguagem pautada na lógica, direcionado ao âmbito matemático.

O matemático alemão, em suas considerações, trata tudo no pensamento objetivo. Este direcionamento adquire extrema importância, na medida em que redireciona o âmbito da discussão filosófica rompendo, assim, com a tradição filosófica que era focada no subjetivo e sempre voltando às observações do "eu" metafísico.

O teórico alemão, apesar de em sua época ser pouco reconhecido, torna-se de suma importância na história da filosofia, pois "O que Frege traz de novo é a ideia de concentrar as investigações filosóficas na linguagem e a ideia de usar meios lógicos para fazê-lo. Para além do mais, desenvolve ele próprio um sistema lógico para apoiar tais investigações." (MIGUENS, S. 2007.p. 84)

\section{Conclusão}

O que foi escrito neste trabalho, como dito desde seus primeiros parágrafos, foi expor a argumentação fregiana a modo sistemático para que se possa deixar explícito os motivos que levaram o filosofo a escrever a despeito de sentido e referência bem como sua influência no surgimento de uma nova ramificação em filosofia que passou a ser uma das principais a serem estudadas globalmente. 
A exposição clara acerca dos conceitos proporcionou Frege fundamentar sua tese segundo a qual a referência é o valor de verdade de uma sentença e esta, junto ao sentido, fundamentam a dita identidade formal.

Apesar de ter fracassado em sua tese logicista, Frege forneceu base para diversas outras investigações, dentre elas as de cunho da Filosofia da Linguagem.

Gostaríamos de ressaltar ainda nesta conclusão o novo direcionamento apontado pelo filósofo da discussão epistemológica, abandonando a forma sujeito-objeto tradicional, é voltada agora a valores lógicos objetivos, distanciando-se do "eu" subjetivo para sua fundamentação, o filosofo alemão foi capaz de proporcionar singularidade em suas obras.

Torna-se imprescindível, para quem se interessar nas investigações da filosofia da linguagem, compreender minimamente sua origem e conseguinte, Frege.

\section{BIBLIOGRAFIA}

RODRIGUES, A. (2008). "Frege e A Filosofia da Linguagem". VERTENTES - Rev. de Pesquisa em Filosofia, n. 33.

BURLANDO, B., G. (2002) "Pensamientos eternos: Platonismo de Augustín y Frege. Teol. Vida", vol.43, no.2-3, p.107-120.

CARVALHO CARDOSO, L.(2014). "Linguagem e Verdade: Uma Analise Logica de Frege. Guarulhos”. [s.n.]

BALDINI, L. J. S. (2011). "Frege e Russel: a questão do pressuposto". Todos os direitos reservados., 11.

FREGE, G. (2011). "Sobre Sentido e Referencia”. FUNDAMENTO - Rev. de Pesquisa em Filosofia, v. 1, n. 3, maio - ago.

. (2009). Logica e Filosofia da Linguagem. seleção, introdução, tradução e notas de Paulo Alcoforado - 2. amp. e ver. São Paulo: Ed. USP. BELUCI CAPORALINI, J.(1994). "Frege: Filosofo da Linguagem? Algumas Considerações Sobre o Pensamento da Maturidade de Frege”. Educ., e Filos. Uberlândia.

MIRANDA, S. (2011). “O artigo 'Sobre Sentido e Referência'”. FUNDAMENTO - Rev. de Pesquisa em Filosofia, v. 1, n. 3, maio - ago. 2011. 
MIGUENS, S. (2007). Filosofia da Linguagem - Uma Introdução. Faculdade de Letras da Universidade do Porto. Maria Adão. Ser Silitito empresa Gráfica Ltda. ALSTON, W. (1963). Filosofia da Linguagem. Rio de Janeiro: Editora Zahar. 